\title{
Governability and Governance from a Complex Perspective
}

\author{
Jorge Brower Beltramin ${ }^{1}$ \\ Facultad Tecnológica \\ Universidad de Santiago de Chile \\ Correo postal 442 \\ Santiago-Chile
}

\begin{abstract}
This article establishes, in the first instance, a reading tour on the conceptual geography of the terms governability and governance, exposing in this journey significant links with other fields of meaning and notions within them, which enable a better understanding of these terms. Then, we propose a rereading from the complexity to enrich the sense of the concepts of governability and governance. This contribution, coming from an epistemic epistemological dimension, contributes not only to increase the semantic density of the concepts but also contributes a form of knowledge whose effect goes beyond the theoretical plane, being expressed in decision-making in the organizational field, whatever his, her nature.
\end{abstract}

Key words: governability, governance, action, complexity

\section{Introduction}

In recent decades, the concepts of governance and governability have obtained great relevance, generally understood as the capacity of societies to provide a system of government that allows for the development of social systems and its individuals.

From our perspective, the meaning of each of these terms is very relevant, as well as the semantic fields that are generated from them or that serve as a platform for their expression. In other words, the putting into practice of the discourse on governance and governability is the visible expression of a set of socio-political processes, of tensions between the various actors who assume the task of governing (at local, national, regional and other levels). Also, it is the recognizable expression of an ideological structure from which a vision of society.

In the first part, this article describes a synthetic journey through the fields of meaning that are generated from the concepts of governability and governance, exposing their fundamental meanings and the derivations that are projected from them. In the same sense, we will explore other semantic fields related to the epistemological perspective of complexity, which in our opinion, could be connected to these expressive units that provides contents and perspectives for explaining social phenomena, to enrich the density of both concepts.

\section{Governability: a conceptual approach}

Studies and analyses in the field of political science and other related disciplines agree that the report presented by Crozier, Huntington and Watanuki (1975), to the Trilateral Commission on the Crisis of Democracy, represents an important turning point, with which the concept of governability is installed on the international political agenda. Factors such as the financial crises, the increasingly diverse and fragmented social demands, together with collective actions that have been acquiring greater social visibility, have demanded a rethinking of this notion (governability), which ultimately allows for the taking up of the challenges that civil society as a whole poses to those who govern or to the governing class.

\footnotetext{
${ }^{1}$ This work is part of the theoretical framework of the research project: Construction of the migrant in the legislative discourse: contributions for new governance on migration processes in Chile", code 031976BB, 2019-20. Responsible researcher: Dr. Jorge Brower B. We are grateful to the Directorate of Science and Technology (DICYT), belonging to the Vice-Rector's Office for Research at the University Of Santiago De Chile, for funding this project.
} 
In this context, the governing or the government, in any of its dimensions (local, national, etc.) must be capable of making effective governance that advances and consolidates democratic projects in the economic and social area.

Regarding to this, we could affirm that the broadest and most general semantic horizon with respect to governance has to do with the existence of political stability that guarantees human development. (Prats, 2001). The procedures that ensure these principles of stability and development should be associated with permanent criteria of flexibility that are capable of gathering the demands and conflicts of complex social dynamics.

In this line of exploration of the nuclear sense that accounts for governability, the concept also appears in terms of principle, as a necessary condition for the development of societies, which must be accompanied by a democratic support or substrate (Prats, 2001). Continuing with the delimitation of the semantic field of governability and the elements of meaning from which it is articulated, we can emphasize a property that we already enunciated before.

Governability initially and substantially means the capacity of political systems to respond to increasingly diverse and complex social demands (Jiménez et al, 2007). Based on this basic and initial conceptual delimitation, the concept of governability is closely linked to that of democracy. In this way, we can observe that what socio-political theories have tried to define is the term that integrates governance and democracy. In fact, these two concepts are already in contact in the report by Crozier, Huntington and Watanuki (1975), which focuses on the capabilities of governability exhibited by the democracies of developed countries. Governability (as is the case with governance), is nothing more than the expression that directly refers to the more or less successful way in which Western democracies operate, which are demanded and stressed by a complex, convulsed and globalized reality. (Jiménez et al, 2007). As we will see later on in this paper, any initial governability framework for development implies the authority to make decisions regarding which paths to adopt, in the current difficult scenario, in order to achieve the desired objectives.

It is not the interest of this work to enter exhaustively into the field of meaning implied by the notion of democracy, but we can point out that theorizing about governability implies it in an unavoidable way, understanding that this political system is the one that should provide the set of rules through which social conflicts are resolved and the guiding principles for the development of the human being are established. In this context, following the proposal of polyarchy, democracy must ensure standards of real participation, equality of vote, informed understanding, final control over the agenda, and inclusion of adults. (Dahl, 1998) These elements, which are fundamental for the articulation of an empirical concept of democracy, are the semantic-ideological basis for governability to function and be validated within a society. This link between governability and democracy, in short between two different semantic fields that appear to be complementary, is very significant in the reflection and theoretical production on these concepts, as they appear to be linked in an almost natural way. The procedures that account for a polyarchy (as we pointed out with Dahl), are presented as a fundamental condition for the existence of democratic governability. Such a basic political state would allow all strategic actors to participate in decision-making and would require those who hold institutionalized powers (economic, political, religious, etc.) to abide by the resolutions emanating from the legislative and executive apparatus within a scenario that safeguards political freedoms and the fundamental rights of individuals.

Just as this strong link between governability and democracy can be observed in the production of political science theories, there is a second concept and its corresponding field of meaning to which governance is linked. This is the market economy understood within the neoliberal model of development. This link is also very significant, since the report of the Trilateral Commission on the crisis of democracy (Crozier et al, 1975), not only is the crisis of democratic governance a concern, but also the preservation of the market economy. For these authors, among whom Huntington (1972, 1991) stands out, the state apparatus must have a set of minimum functions, so that it does not hinder the production and re-distribution of wealth. Through this conceptual linkage, governability is charged with a sense oriented towards the reduction of the state in terms of its intervention/regulation of the different actors and institutions on which societies are articulated. This second linkage (neoliberal governability-model) has had an interesting critical metal reading from Latin America. Authors such as Kauffman (2002), have pointed out that corruption in our region has given way to bad neoliberal governance. From there, their re-reading of good government and consequently of an optimization of governability, has to do with the practice of authority considering traditions and institutions that are oriented towards the common good.

This aforementioned idea has a place in a framework of respect for citizens in relation to the economic and social interactions that involve them. In this same line of critical/conflictivist re-reading, Rottman (2002) contributes a perspective that understands governability within liberal democratic models sustained in turn by a neo-liberal model of development. Thus understood, governance (in the Latin American context) has finally translated into a series of normative operations that only strengthen the logic from which the consumer society is stimulated. Rottman himself 
(2002), concludes that in the name of this conception of governability new networks of exploitation and new forms of colonialism have been established in Latin America.

As can be seen, the concept of governability has entered into a dynamic of meaning with important polysemic features. It is clear that the ideological associations developed with respect to this notion have been giving it a semantic thickness or density that makes it more complex. As Prats (2001) warns, the term has been used in various fields and areas, not having a correspondence that clearly defines it. On the other hand, Prats (2001) adds that the lack of a conceptual delimitation between governability and government makes it necessary to advance in the conceptual clarification regarding the fields of meaning of each one of them.

From our perspective, we know that all linguistic-conceptual materiality acquires its meaning in a dynamic way and depending on the conditions of its production, giving it a rich polysemy that is sometimes unembraceable. For this reason, we are interested in this reading as it establishes significant semantic links and simultaneously stresses the term governability, deploying links of meaning that account for a whole discursive/conceptual geography through which we try to make explicit how it is and how it should be the action of governing or the governing of complex societies that, through their demands, are beyond any ideological apparatus and their corresponding biased and arbitrary worldviews.

\section{2.-Governance: from discourse to action}

The socio-political theory has evolved in recent times from the theme/concept of governance, understood in a broad way as the capacity of political systems to take charge of multiple social demands, towards a theorization and therefore a conceptual production on the notion of governance, referring specifically to the procedures that make possible horizontal interaction between the public and private spheres and social actors, in the broader context of an institutionally that allows for progress in large social agreements at the macro level and organizational ones at the micro level. Understood in the specific field of management, the concept of governance is validated based on the World Bank's reports (1989) on the development crisis suffered by the sub-Saharan African region. In this context, it warns about the need for good public management in relation to high levels of corruption and the processes of privatization of public entities. In this report, these elements are connected to the adoption of the market economy model based on a clearly neoliberal ideology. As in the report of the Trilateral Commission on the Crisis of Democracy (Crozier et al, 1975), which refers to the concept of governance, the work of the World Bank (1989) is concerned with good governance, that is, governance in the sphere of liberal democracies. A good conceptual definition of governance is provided by those who emphasize that the new style of government at different levels must allow for increasing degrees of cooperation and interaction among the various actors in a society or organization, whether they are State, private or other types of organizations or origin (Mayntz, 2000). This cooperation and interaction would guarantee the articulation of a new social order. In this way, the governance that we have already defined before, as that general capacity to govern, would be dependent on the more specific variable represented by the concept of governance as pointed out by Prats (2003) and Aguilar (2007) among others. This, since the latter produces the rules of the game for an institutionally in which the set of interactions and exchanges that finally account for a better capacity to govern are made possible. Governance thus acquires the status of a discourse for action, as conceived by the language of Berkeley's pragmatic philosophers in the 20th century. (Searle, 1994). Also from the philosophical episteme of language, governance is structured as a vector towards knowledge/doing, permeable and connected to the multiplicity of variables that exhibit concrete problems, as Wittgenstein (2017) already warned in the last stage of his philosophical project.

This action orientation presented by governance, reflects the problems and demands of more or less organized individuals in the broad social structure. In order to put itself in a performative movement, it is articulated with three discursive components. The first of these has to do with the network of policies, an element/characteristic that for authors such as Zurbriggen (2003) and Gaudin (2002), constitutes a fundamental question for understanding the contemporary concept of governance. This policy network is basically related to decision-making and the execution of decisions, through social coordination in various dimensions of social/organizational life, such as self-government or the production of contractual policies, actions that are characteristic of horizontal coordination and not of a vertical practice of authority. In this first linkage, the concept of network matters since it characterizes new forms of government beyond the limits proposed/imposed by the State and market regulations.

The second discursive component linked to governance that we want to mention is that of public policies. In the context of the so-called New Public Management (NPM), it is pointed out that public policies seek to make decisions from the State more assertive, optimizing the process of governing (Aguilar, 2007). It can be directly inferred from this conceptual linkage that the regulations, procedures and execution of these (involved in all public policies) constitute the concrete form through which governance is fully updated. In the private sphere, this second component is also clearly 
manifested in the large organizations that have a structured and formal policy for the operation of all their estates and individuals involved in them.

The third important discursive component in its link with the concept of governance is that which has to do with territorial policies. This is a contribution by Müller (2002), who proposes the existence of horizontal or territorial policies as opposed to the existence of vertical sectoral policies. The former (horizontal or territorial) are carried out by territorial units within a sub-national dimension and in that sense of local territorial governance (Jolly, 2007). In this case, these would be regulations and procedures that adjust in a more real, pertinent and legitimate way to the needs and demands of specific communities within a larger territory such as the national one. From our metal reading of the conceptual journey and the various twists and turns that the notion of governance takes, we believe that this last link is of great relevance since territorial policies, understood in horizontal terms, allow us to collect and assume in concrete regulations, cultural and idiosyncratic variables developed from local communities and in this sense, can better account for the multiple demands of these communities.

In summary, these three links to the concept of governance, projected to fields of meaning articulated from the promotion of better public policies, are giving rise to a theory of governance that considers the contexts of production of these policies as a key variable for their formulation (Mayntz, 2000). Indeed, these statements warn that governance must take charge of the transformations suffered by the functions of government in a scenario of globalization/relocation, an issue that establishes a major challenge for good government in any of its dimensions (local, regional, national, etc.) (Jessop, 1998). In this sense, governance is defined as the set of interactions between all types of public and private organizations, in addition to civil society, that are oriented towards the resolution of conflicts and problems of specific communities, communities of life that are found in very defined temporal and spatial coordinates, with historical and identity burdens from which they tension, through conflicts, and produce their demands for the solution of those conflicts. (Pierre \& Peters, 2000), (Meuleman, 2009). Thus, the context variable is considered as an element that directly conditions the articulation and application of effective governance. In this direction, the current development of a theory of governance is sustained from a complex epistemic perspective since, in short, the decision-making process to achieve certain objectives includes a very wide plurality of variables, many of which cannot be imposed from the central government, but are in full development and evolution in local, territorial or microterritorial spaces.

In the Latin American context, theoretical production on the concept of governance has been rather scarce. The installation of this term in Latin America has had to do with entities related to international cooperation, such as the World Bank (WB), the Inter-American Development Bank (IDB), the United Nations Development Programme (UNDP) and their projects to help underdeveloped countries. Just as we warned (previous section), about greater and better governance in our region and the dangers of corruption in public and private spheres, the same thing is happening with governance. Both the UNDP (UNDP 1997) and the WB (1997) note the need for transparency and corruption-free processes for better governance. It is also necessary to emphasize that the recommendations of this type of international organizations are made within the logic of a neoliberal state model and therefore, the efforts involved in this notion of governance are oriented towards strengthening the free market. Governance here appears to be linked to neoliberal reforms that lead to full development, an additional concept associated with a reduction of the State, commercial liberalization, privatization of public institutions, and strengthening the right to private property.

Finally, the conception of governance formats must be carried out through a complex lens, in order to understand and interpret also a complex phenomenon: the development of cultures in any of their organizational dimensions (local, subnational, national, regional, etc.)

\section{Governance and governability from a complex epistemological perspective.}

As we have explained towards the end of the previous section, the new theories of governance and also those dealing with the general concept of governance, are forced to put into action a critical and contributive reading, which nourishes such concepts, not simply to give them more semantic density, but to effectively translate them into better governments. In this context, we propose that both the conceptual development and the application of governance should be linked to a previous epistemological instance contributed by complexity, installed as an enriching contribution from the instance of theorization on these terms. In such an analytical/propositive direction, we find interesting the critical contributions that point to an attitude of resistance in the face of a conception of an exclusive State and a neo-liberal society that only leads to new forms of exploitation and colonialist territorialization (Rottman, 2002). In this diagnostic direction, it is a challenge that translates into the need to generate alternative models of governance and administration, deepening the multiple logics that operate in civil society as well as the functions of the State that represent legitimate articulators for a redefinition of democracy from a counterhegemonic position (de Souza 
Santos, 2004). It is not the same to advance on a social or organizational development plan tied to predetermined economic or political models, as it is to advance on a complex geography expressed through inter-subjective linkages conditioned by diverse modeling devices of the subjects that interact in that geography.

Consequently, governance emerges as a concept/action that is particularly stressed in its linkage to specific human realities. Indeed, associated with concrete policies, local governments and their management on the ground, governance faces a wide range of social transformations that require its attention and the resolution of the problems contained therein. Variables such as population growth and its associated needs, the coexistence of different generations, the various geographical and cultural migrations, the multiple family structures and the different processes of social segmentation (which also imply territorial segmentation), constitute some of the characteristics of social development that governance formats must include.

From our perspective and in the face of these challenges regarding the modeling of governance formats relevant to the contexts in which they will be implemented, it is necessary to consider social organizations and the transformations they undergo, as complex realities. This is an epistemological consideration, which has as a reference the works of Morin, in which this researcher shapes a paradigm of complexity. From this proposal, we are interested in certain aspects that, in our opinion, should be incorporated into all theorization in the field of social sciences, including certainly those of a sociopolitical nature, from which the concepts of governance and governability have emerged.

In the first place, this epistemic perspective allows us to understand the social fact and its development as a complex system, that is, in Morin's terms (García, 2006), not reducible to a limited set of variables, situations or phenomena that can be apprehended in their totality and at once. On the contrary, it is an understanding that unfolds in a process of knowledge in permanent construction. In this sense, societies and their development demand to be conceived from particular morphologies semantically charged with contents of greater or lesser significance, linked from criteria that obey different logics and validation variables that are also diverse and different. All this constitutes a complex reality that resists being explained from a simple thought (like that of the Cartesian linearity) and that therefore demands a complex thought that goes beyond the simplification, in the search or exploration of the greater amount of elements that are put in game to articulate the societies and the cultures that are generated and developed from and in the diversity. This diversity of actors, materials and spaces, among other variables, in the light of complexity, should not be mutilated with the illusory aim of constructing operational fictions oriented to create certainties that obviously do not account for the social fact that is expressed within a historical and contextual process from which it is nourished.

Thus, the current challenge of socio-political theories for the approach of concepts such as governance and governability has to do in the first place, with the understanding of societies and their development in complex terms. Already Durkheim (1937), tried to develop explanatory theoretical approaches to the articulation of complex societies. We mention this because his efforts can be linked to current approaches to a complex organization/society. Indeed, Durkheim visualizes the genesis of this complexity in the first social congregations expressed in the horde. This primitive social form would be the evolutionary antecedent of all subsequent forms of social organization.

The horde manifests a society without order based mostly on unregulated and less regulated actions and exchanges. From this diagnosis, Durkheim tries to explain the conformation of complex societies as a succession of computer aggregates in a sort of recursive articulation from a simple society. Regarding to this,Durkheim points out that this succession of aggregates produces the social segmentation that would shape a more complex structure of society, which he calls a clan. (Durkheim, 1937). From Durkheim's point of view, societies become more complex as they develop recursive folds on themselves generating more sophisticated combinations of interaction. In synthesis, the definition of complex social morphology in Durkheim, has to do in the first place, with the successive addition of simple aggregates, folds of sense that are linked to, in a second instance, give form to an architecture of greater sophistication that gives account of the social organization. This complex social morphology places greater demands on those who lead organizational systems and, as we pointed out earlier, makes decision-making more complexes, both in public and private senior management. This complexity clearly implies the resolution of diverse problems beyond predetermined models that, in fact, distort the most genuine and real demands.

Following the initial explanation given by Durkheim, regarding the conformation of complex societies, this is enriched and updated from the contemporary anthropology that has within its epistemological platform the principles of Morinian complexity. In this context, Mier Garza (1994) adds that social complexity increases thanks to new forms of non-regulated collective alliances, the development of individual identities that are linked, through diverse modalities to the collective and multiple heterogeneous dynamics that decisively characterize the social structure and the consequent cultural density that is produced from it. The understanding of the organizational/social as a complex fact, (already exposed), has simultaneously meant the generation of a theoretical thought that takes charge of that 
complexity and that therefore opens, from our perspective (Brower, 2008), to the multiple forms in which its variables or components are linked and consequently, to the potential stability/instability of those links.

In the context of Morin's theoretical project $(1984,1994)$, complex thought must reconstruct the process of knowledge, incorporating the regularities and irregularities that are expressed in society and its cultures and must be described and explained as an integral phenomenon. The theorization of social complexity thus promotes an analytical activity that, as we have pointed out in another work (Brower, 2008), shortens the distance with what is known, warning in that process of rapprochement, the symbolic articulations through which a culture is expressed, an analytical consideration that should not be understood as definitive.

Undoubtedly, the principles that inspire complex thought should be considered by the social sciences in general, by political science and by organizational theories. As lucidly indicated by Morin (2005), we must be capable of facing the challenges of the 21st century, respecting human diversity, that is, multiculturalism and its coexistence in common spaces or territories. The cultivation of affectivity, fraternity and the capacity to love through a deep understanding of the other, constitute a basic initial state to set in motion an integral and non-fragmented modality of (complex) thought. These principles/concepts are closely linked to the art of governing, leading and leading, and are therefore closely linked to the notions of governability and governance, as set out in the first two sections of this work. Both the general capacities of good government and the policies implemented within the different forms of human organization should consider this conception of a complex society, since this comprehensive option necessarily implies generating formats of government based on flexible strategies, adaptable to very different conceptions of life.

Thus, the critical warnings we referred to at the beginning of this section, which had to do with the need to generate governance formats from local spaces and times, identifying and including the variables on which concrete societies are articulated and developed, shape an epistemic lens that allows us to understand organizational structures as complex systems. Thus, the resistance to the conception of excluding states, which are applied uncritically in different parts of the world, coincides with the initial approach to the complex understanding of social reality (Rottman, 2002). Similarly, it seems relevant to us to consider the need to understand the diverse logics that operate in the development/construction of society, logics that are also expressed in social dynamics as the genuine articulators for the constitution of counterhegemonic democracies, capable of establishing a valid dialogue with the dominant systems, generated basically from Europe and the United States (Souza Santos, 2004).

Now, as a final consideration regarding the contribution of the complex reading of the conceptual formats of governance and governability, it is necessary to point out, in the direction of understanding and including different logics in the articulation and development of societies, that both the conceptualization and the protocols of implementation of policies that ensure governance and genuine governance with respect to the needs and demands of a human organization, be assumed from an interdisciplinary view, which is also an unavoidable issue or requirement for the understanding of complex systems. As we have pointed out in other works (Brower, 2008, 2010a, 2010b), interdisciplinary allows for diverse theories and methodologies to dialogue on specific topics in order to better understand the intractable fabric of culture. In this sense, Sinaceur (1983) considers interdisciplinary as an instance in which different points of view converge, making experts give a limited vision on a topic that, when interacting with other points of view, articulate or shape an enriched explanatory synthesis on that topic.

\section{Conclusion}

Once this conceptual tour of the terms governability and governance has been concluded, a tour that does not claim to be exhaustive and that therefore only stops at those semantic fields that we have found interesting in order to give them greater semantic depth, we can establish certain links of meaning that can cooperate in their reading and understanding.

In the first place, the concepts of governability and governance have sometimes been used indistinctly to refer to the exercise of good government and the competencies that this exercise implies. Thus, governance appears to be linked to certain rather general capacities to govern, capacities which, in turn, are understood or conditioned within a democratic political framework and in direct consonance with the neo-liberal market economic model. This conceptual cluster (set of links and associations between terms), is problematized from the political sciences or general political science around a central concern: the weakening of democratic systems in the world (particularly the third world) and the urgent need to strengthen them. At this problematic conceptual juncture, it is necessary to warn that the theoretical interest insists on a greater territorialization/validation of democracy, but it is strongly linked to free market economies. It is not surprising then that international organizations such as the World Bank, are the ones that issue the greatest number of reports and statements on the situation of European, African and Latin American economies. In fact, from 
this perspective, these reports link the functioning of the market with the state of health of emerging or more consolidated democracies. This clutch or connection/combination of concepts nourishes the term governance.

Finally, the topic/topic of corruption always appears in this neoliberal democratic conception, since this phenomenon alters the legal flow of the market, generates losses, tax evasion and money laundering that come from clandestine markets such as drug trafficking, among others.

On the other hand, the concept of governance has had a very interesting development and semantic enrichment in the last decades. This term does not refer to the general capacity or capabilities to govern but is directly linked to the public policies that are implemented for the organization of societies and, on the other hand, to satisfy the demands of civil society, which are increasingly broad and require a faster response. In this way, governance is understood within defined and stable constitutional frameworks, a set of laws that guarantee a good distribution of power, and regulatory norms through which these laws are executed.

In this context, the theoretical problematization regarding the notion of governance has been installed in a critical way, regarding the task of generating formats for governance that are adapted to specific territories, gathering the multiple identity and development variables that the communities have to project themselves into the future. In this direction, public policies appear as the key expression that should contain, from this analytical/critical viewpoint, the local logics from which concepts such as progress or development are understood. This topic represents a turning point in the theoretical debate on governance. In fact, we have been able to see how, in Latin America, researchers in this area question the formats of governance uncritically transferred from Europe to our lands. This problematization, which implies a questioning of the very concept of democracy and clearly of the free market economy, is visualized in our conceptual journey.

In this way, we can conclude that political theories are increasingly confronting the demands of civil society, in the sense of articulating or constructing public policies that represent it and that therefore account for the content that matters to that society. This is the central point of the new governance formats and therefore of their deeper and more genuine conceptualization.

Faced with this challenge, we conclude our work with a section that connects the conceptual journey on governance and governability with an epistemological-theoretical paradigm, which offers or contributes an epistemological lens not only for the conceptual enrichment of these terms, but also invites us to a performative operationalization of them. It is about the complex perspective or look from the complexity, whose principles make clear the need to understand the greatest amount of variables in the articulation and development of societies understood by this, as a complex fact. Complexity in this context should not be understood as a phenomenon that is difficult to explain or inaccessible. On the contrary, this epistemic proposal expands the comprehensive horizons of social reality, enhancing in the specific case of the act of governing, its conceptualization and translation into the practical dimension of making a better government. This linkage/connection with the principles of complexity remains here as an initial and therefore unfinished proposal that needs to be deepened through an interdisciplinary dialogue, which will finally be able to produce better forms of organization of life in society.

This contribution also sheds light on those who must make decisions within complex systems. Government, management, in any organizational dimension should adopt a critical perspective. This means a detailed review of the procedures, protocols and regulations that are part of a standardization of protocols. Social realities, organized in different ways, show an instability and dynamism that permanently overflows the procedures already elaborated and applied. We must constantly be modifying, correcting and incorporating new elements to them so that they manage to gather in a productive way, the problems and demands of the social systems in any of their scales or dimensions. Decision-making, in the context of complexity, should, based on the considerations made in this work, be very flexible and porous to the changing world we have built, with high degrees of chaos that, as layers of meaning, adhere to the functionality of the systems, making them very insecure.

Finally, we believe that uncertainty takes over the human action, in a vertiginous way, and therefore to govern and apply the actions of a good government, must start by a rather Adamic exposure to the realities to which we have given shape, Adamic in the sense of unprejudiced, carrying in our toolbox, lenses of wide spectrum that can give us a vision as inclusive as possible on the variables that account for a problem or demand. What we can no longer carry in this toolbox, are rigid algorithmic schemes, logocentric models or sclerotic ideologies, which do not ensure anything for the understanding of the present or even less of the future, even if they have ever told us something very poor and reduced about the past. 


\section{References}

Aguilar, L.F. (2007). El aporte de la política pública y de la nueva gestión pública a la gobernanza. En Revista del CLAD Reforma y Democracía, №39, Caracas.5-32.

Brower, J. (2008). Implicancias epistemológicas del pensamiento complejo para la articulación de la una semiótica de la cultura. En Revista Estudios de Filosofía N³7. Universidad de Antioquia. Medellín. Colombia.30-60.

Brower, J. (2010a). El valor semiótico y Dialógico de las nuevas epistemologías. En Revista Observaciones Filosóficas. $\mathrm{N}^{\circ}$ 10. Universidad Católica de Valparaíso. (On line) Available: https://www.observacionesfilosoficas.net/elvalorsemiotico.htm (20, july,2018)

Brower, J. (2010b). Reflexiones Teóricas Sobre la Dimensión Semiótico-Discursiva de la Ideología Política Revista RE - Presentaciones. Periodismo, Comunicación y Sociedad. Escuela de Periodismo Universidad de Santiago.Año 3, Número 6. 61- 72.

Crozier, M.J., Huntington, S.P., Watanuki, J., (1975). The Crisis of Democracy: Report on the Gobernability of Democracies to the Trilateral Commission. New York UniversityPress.

De Souza Santos, B. (2004). Democratizar la Democracia: Los caminos de la democracia participativa. México: FCE.

Gaudin, J.P. (2002). Pourquoi la gouvernance?. Paris: Presses de Sciences Po.

García, R. (2006). Sistemas complejos. Conceptos, métodos y fundamentación epistemológica de la investigación interdisciplinaria. Barcelona: Gedisa.

Jessop, B. (1998). The Rise of Governance and the Risks of Failure: The Case of Economic Development. International Social ScienceJournal. Vol. 50, $\mathrm{n}^{\circ} 155.29-45$.

Jolly, J.-F. (2007). Gobernabilidad territorial y descentralización en Colombia: ¿regir el territorio o gobernar los territorios? A propósito de la política pública de descentralización en Colombia entre 1982 y 2002. Conferencia expuesta en el Foro Internacional “Globalización, Gobernabilidad y Territorio”. Escuelas Superior de Administración Pública. Bogotá, 29 y 30 de noviembre.

Prats i Catala, J. (2001). Gobernabilidad democrática para el desarrollo humano: marco conceptual y analítico. En Instituciones y Desarrollo, $\mathrm{N}^{\circ} 10$, Barcelona. 103-148.

Prats i Catalá, J. (2003). El concepto y el análisis de la gobernabilidad. En Instituciones y Desarrollo. $\mathrm{N}^{\circ}$ 14-15, Barcelona.239-269.

Jiménez, W.,Ramírez, C., Roncancio, P. (2007). Gobernabilidad y gobernanza en la transformación de la acción pública: propuesta teórica y estudio de caso. Bogotá: ESAP Publicaciones.

Dahl, R.A. (1998). Democracy. Yale UniversityPress.

Durkheim, É. (1937). Les regles de la méthodesociologique. París: PUF.

Huntington, S.(1972). El orden político en las sociedades en cambio. Buenos Aires: Paidos.

Huntington, S. (1991). The Third Wave: Democratization in the Late Twentieth Century. University of Oklahoma Press.

Kaufmann, D. (2002-2003). Rethinking Governance.EnReporte Global de Competitividad.

Pierre, J. \& Peters, G. (2000). Governance, Politics and the State.Basingstoke: Macmillan.

Rottman, M. (2002). La gobernabilidad: ¿ un problema teórico-práctico?. En Salinas, D. y Jiménez, E. (coordinadores), Gobernabilidad y Globalización. Procesos recientes en América Latina. México: Gernica.

Banco Mundial. (1989). El África Subsahariana: De la Crisis al Desarrollo sustentable. Una perspectiva de largo plazo. Washington, D.C.: BM/Oxford UniversityPress.

Banco Mundial. (1997). Informe sobre desarrollo humano 1997. El Estado en un mundo en transformación. Washington, D.C.: BM/Oxford UniversityPress.

Mayntz, R. (2000). Nuevos desafíos de la teoría de governance.. En Instituciones y Desarrollo. Nº 7. Barcelona. 35-51.

Meuleman, L. (2009). The Cultural Dimension of Metagovernance: Why Governance Doctrines May Fall. PublicOrganizationReview. 49-70.

Mier Garza, R., (1994). Vicisitudes de la inestabilidad: apuntes para una reflexión sobre la noción de complejidad en antropología, En Boletín de Antropología Americana, México, Instituto Panamericano de Geografía e Historia, vol. 29, 1994.

Morin, E. (1977). Tomo 1. La nature de la nature. En La Méthode. París: Editions du Seuil.

Morin, E. (1984). Ciencia con conciencia. Barcelona: Anthropos.

Morin, E. (1986). Tomo 3. La connaissance de la connaissance. En La Méthode. París: Editions du Seuil.

Morin, E. (1994). Introducción al pensamiento complejo. Barcelona: Gedisa.

Morin, E. (2005).Esperando nuestra mariposa. IniciativaSocialista. N77.(On line) Available: http://www.inisoc.org/. (2 april 2012)

Muller, P. (2002). Las políticas públicas. Bogotá: Universidad Externado de Colombia.

Searle, J. (1994).Actos de habla, Barcelona: Planeta-De Agostini. 
Sinaceur, M.A. (1983). ¿Qué es interdisciplinariedad? En Apostel, L. et al. Interdisciplinariedad y ciencias humanas. Madrid: Tecnos/Unesco. 23-31.

UNDP, (1997). GovernanceforSustainable Human Development. Nueva York: UNDP.

Wittgenstein, L. (2017). Investigaciones Filosóficas. Traducción del original alemán, introducción y notas de Jesús Padilla Gálvez. Madrid: Editorial Trotta.

Zurbriggen, C. (2003). Las redes de políticas públicas: una revisión teórica. Barcelona: Institutointernacional de Gobernabilidad de Cataluña (ColecciónDocumentos). 